\title{
COVID-19 in Chronic Kidney Disease: The Impact of Old and Novel Cardiovascular Risk Factors
}

\author{
Manuel Alfredo Podestà ${ }^{a}$ Federica Valli $^{b} \quad$ Andrea Galassi $^{a} \quad$ Matthias A. Cassia ${ }^{a}$

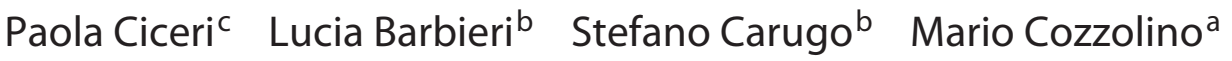 \\ aRenal Division, Department of Health Sciences, ASST Santi Paolo e Carlo, University of Milan, Milan, Italy; \\ ${ }^{b}$ Cardiology Unit, Department of Health Sciences, ASST Santi Paolo e Carlo, Milan, University of Milan, Milan, Italy; \\ 'Department of Nephrology, Dialysis and Renal Transplant, Renal Research Laboratory, Fondazione IRCCS Ca' \\ Granda, Ospedale Maggiore Policlinico, Milan, Italy
}

\section{Keywords}

Coronavirus disease 2019. Chronic kidney disease .

Cardiovascular disease · Risk factors · Dialysis

\begin{abstract}
Cardiovascular disease is a frequent complication and the most common cause of death in patients with CKD. Despite landmark medical advancements, mortality due to cardiovascular disease is still 20 times higher in CKD patients than in the general population, which is mainly due to the high prevalence of risk factors in this group. Indeed, in addition to traditional cardiovascular risk factors, CKD patients are exposed to nontraditional ones, which include metabolic, hormonal, and inflammatory alterations. The global severe acute respiratory syndrome coronavirus 2 (SARS-CoV-2) pandemic has brought novel challenges for both cardiologists and nephrologists alike. Emerging evidence indicates that coronavirus disease 2019 (COVID-19) increases the risk of cardiovascular events and that several aspects of the disease may synergize with pre-existing cardiovascular risk factors in CKD patients. A better understanding of these mechanisms is pivotal for the prevention and treatment of cardiovascular events in this context, and we believe that additional clinical
\end{abstract}

and experimental studies are needed to improve cardiovascular outcomes in CKD patients with COVID-19. In this review, we provide a summary of traditional and nontraditional cardiovascular risk factors in CKD patients, discussing their interaction with SARS-CoV-2 infection and focusing on COVID-19-related cardiovascular complications that may severely affect short- and long-term outcomes in this high-risk population.

c) 2021 S. Karger AG, Basel

\section{Introduction}

Cardiovascular events are currently the most common cause of death in patients with CKD and represent an increasingly prevalent health care problem globally [1]. This association is partly due to the fact that traditional cardiovascular risk factors also drive CKD development and progression. In turn, progressive renal function deterioration entails several metabolic, hormonal, and inflammatory alterations falling under the category of non-

Manuel Alfredo Podestà, Federica Valli Contributed equally to this work.

karger@karger.com

(C) 2021 S. Karger AG, Basel

www.karger.com/bpu

Karger ${ }^{\prime}=$
Mario Cozzolino

Renal Division and Laboratory of Experimental Nephrology, Dipartimento di Scienze della Salute, ASST Santi Paolo e Carlo Hospital, Università di Milano

Via A. di Rudinì, 8, IT-20142 Milan (Italy)

mario.cozzolino@unimi.it 
traditional risk factors, which predispose to cardiovascular morbidity.

The advent of the severe acute respiratory syndrome coronavirus 2 (SARS-CoV-2) pandemic has brought novel challenges for both cardiologists and nephrologists, especially in the management of patients with renal failure $[2,3]$. Indeed, the SARS-CoV-2 outbreak remarked the inherent frailty of CKD patients and the strong link that exists between CKD and cardiovascular events. Cardiac injury occurs in approximately $20-25 \%$ of hospitalized patients with coronavirus disease 2019 (COVID-19) [4], and cardiovascular events and comorbidities are among the most important drivers of mortality in this context [5-7]. Emerging evidence also indicates that CKD is a key risk factor for mortality in patients with COVID-19 $[8,9]$. Kidney involvement with hematuria and proteinuria was found to be an independent predictor of in-hospital death [10]. SARS-CoV-2 tropism for the kidney and systemic responses to the infection may partly account for the high incidence of acute kidney injury and mortality due to renal-related complications reported in observational studies [11]. Moreover, several alterations induced by SARS-CoV-2 infection may synergize with other cardiovascular risk factors in CKD patients, thus increasing the risk of cardiovascular events.

In this review, we provide an overview of traditional and nontraditional cardiovascular risk factors in CKD patients, discussing the effects of SARS-CoV-2 infection in this context and focusing on COVID-19-related cardiovascular complications.

\section{Traditional Risk Factors}

Traditional risk factors are those that have been historically identified in the Framingham cohort study [12, 13], which are currently used to assess cardiovascular risk in the general population. Even though these traditional risk factors are insufficient to explain the burden of cardiovascular morbidity in CKD [14], they still account for a significant fraction of the cardiovascular risk in this population.

Indeed, CKD and cardiovascular disease share many of the traditional risk factors identified in the Framingham study. In addition to nonmodifiable risk factors such as older age and male sex, which are associated with the development of CKD and are important predictors of progression to ESRD [15], diabetes is a major cardiovascular risk factor that also drives renal function deterioration. Diabetes currently accounts for approximately $40 \%$ of ESRD cases in the United States [1], and the combination of diabetes and CKD is associated with an increased risk of major cardiovascular events and higher mortality rates $[16,17]$. Consistently, diabetes is independently associated with cardiovascular disease in patients on maintenance dialysis $[18,19]$.

Since smoking has been shown to promote CKD development and progression [20], it is conceivable that a high frequency of CKD patients are active or former smokers. Similarly to the general population, smoking has been associated with an increased risk of cardiovascular events in CKD patients, with an $11 \%$ risk increase for each 5 pack-years compared to nonsmokers [21].

The prevalence of hypertension in CKD patients is extremely high and increases along with CKD stages, exceeding $90 \%$ in hemodialysis patients in some series [22]. Cardiovascular outcomes are substantially worsened by the presence of systolic hypertension in nondialysis dependent patients $[21,23]$, and more strict blood pressure targets seem to confer a benefit on mortality rates [24]. The relationship between mortality risk and blood pressure in hemodialysis patients is U-shaped, possibly due to the fact that low blood pressure values in these patients may indicate a higher burden of comorbidities, such as heart failure [25].

Arterial hypertension is one of the main drivers of left ventricular hypertrophy $(\mathrm{LVH})$; consistently, $\mathrm{LVH}$ is a frequent finding in $\mathrm{CKD}$ patients and is present in over $70 \%$ of predialysis patients [26]. Similarly to the general population, $\mathrm{LVH}$ predisposes to the development of arrhythmias and heart failure and is independently associated with cardiovascular morbidity and mortality in CKD [27].

Dyslipidemia is a common complication of CKD, with several possible hematochemistry patterns that depend on CKD stage and on the degree of proteinuria [28]. Interestingly, the strength of the association between lowdensity lipoprotein levels and cardiovascular outcomes declines as renal function deteriorates, suggesting that interventions aimed at controlling dyslipidemia such as statins are likely to have a relatively higher impact in early stages of CKD [29]. In patients on dialysis, despite an even higher prevalence of lipid disorders and an exceptionally high cardiovascular morbidity, the effect of lipidlowering drugs is less evident $[30,31]$, suggesting that other factors are likely to play a major role in these patients.

The increasing prevalence of obesity worldwide has well-known direct consequences on the risk of cardiovascular disease in the general population. In this context, 
several observational studies have demonstrated a significant association between obesity and CKD [32]. In addition to downstream consequences of obesity such as diabetes and hypertension, this condition also determines compensatory glomerular hyperfiltration and increased inflammatory/oxidative stress, which result in renal damage over time and determine CKD development. Recent data, however, suggest that obesity in CKD patients may not lead to increased cardiovascular mortality; moreover, obesity could also be a protective factor in patients on dialysis, due to its counter-effects on protein-energy wasting and malnutrition [33].

\section{Nontraditional Risk Factors}

Seminal studies have consistently demonstrated the existence of a strong association between reduced renal function and cardiovascular disease, which is not fully explained by traditional risk factors [14, 34, 35]. Increasing degrees of albuminuria, one of the earliest markers of $\mathrm{CKD}$, have been consistently and independently associated with worse cardiovascular outcomes even in patients with normal renal function $[36,37]$. This excess risk is largely due to the metabolic, hormonal and inflammatory alterations that accompany CKD, which have a profound impact on cardiovascular morbidity [38].

Sympathetic nervous system activation is an early event in CKD, which progressively worsens as renal function deteriorates [39, 40]. Sympathetic overdrive promotes the release of catecholamines and renin, which result in increased vascular resistance, renin-angiotensin system (RAS) activation and expansion of the extracellular volume, ultimately leading to cardiac remodeling and fibrosis [41]. Volume overload may occur in up to half of nondialysis-dependent CKD patients and is associated with a higher requirement of antihypertensive medications and increased arterial stiffness [42]. Fluid retention is present in virtually all patients on maintenance dialysis, and higher interdialytic weight gains have been consistently associated with cardiovascular mortality [43].

CKD is also characterized by a state of chronic inflammation [44], which is enhanced by neurohormonal imbalances. Persistent inflammation leads to dysfunctional responses to pathogens and contributes to premature vascular aging [45]. This state is further exacerbated in patients on maintenance dialysis, in whom complete renal function loss leads to the accumulation of inflammatory mediators. Up to 1 quarter of the medium-molecularweight uremic toxins currently identified, which are not efficiently removed by conventional dialysis, are indeed cytokines or other proinflammatory molecules [46]. These circulating mediators, such as IL- 6 and TNFa, have been associated with LVH in patients with CKD [47]. Moreover, elevated levels of C-reactive protein, an acutephase reactant that contributes to accelerated atherogenesis [48], have been associated with cardiovascular events in CKD patients $[49,50]$ and have been found to predict cardiovascular mortality in patients on maintenance hemodialysis [51].

Inflammation is also tightly linked to oxidative stress, a state of imbalance between oxidant radicals and antioxidant systems. The abundance of reactive oxygen species is directly correlated with CKD stage and peaks in patients on maintenance hemodialysis [52]. In CKD patients, oxidative stress is enhanced by the angiotensinmediated activation of NADPH-oxidase [53] and by the action of uremic toxins such as indoxyl sulfate and asymmetric dimethylarginine, which inhibit nitric oxide synthase $[54,55]$. Oxidative stress promotes endothelial dysfunction by reducing nitric oxide concentration, thus favoring arterial stiffness and $\mathrm{LVH}$, as well as the development and progression of atherosclerosis [56, 57].

Mineral disorders have a major impact on cardiovascular outcomes in CKD patients. In particular, hyperphosphatemia and high levels of fibroblast growth factor 23 (FGF23) are common features in CKD, and both increase the risk of cardiovascular disease at multiple levels.

Despite the relative stability of serum phosphate concentrations until later CKD stages, derangements in phosphate metabolism are indeed an early consequence of CKD. Even small increases in circulating phosphate levels inside the normal range have been associated with higher cardiovascular morbidity and mortality rates [58]. In this context, phosphate acts as a vascular toxin, inducing endothelial dysfunction and promoting vascular calcification of the media [59], an active process in which vascular smooth muscle cells proliferate, increase collagen and extracellular matrix production, and undergo a phenotypic transdifferentiation into osteoblast-like cells, which are ultimately responsible for calcium deposition [60]. Medial calcifications increase arterial stiffness, leading to altered pulse pressure and LVH. In CKD patients, medial calcifications frequently coexist with intimal, atherosclerotic calcifications, which may predispose to plaque rupture and thrombosis. Overall, the presence of vascular calcification, in particular coronary artery calcifications, has emerged as a strong predictor of cardiovascular morbidity and mortality in CKD patients [61]. Moreover, vascular calcifications are frequently accom- 


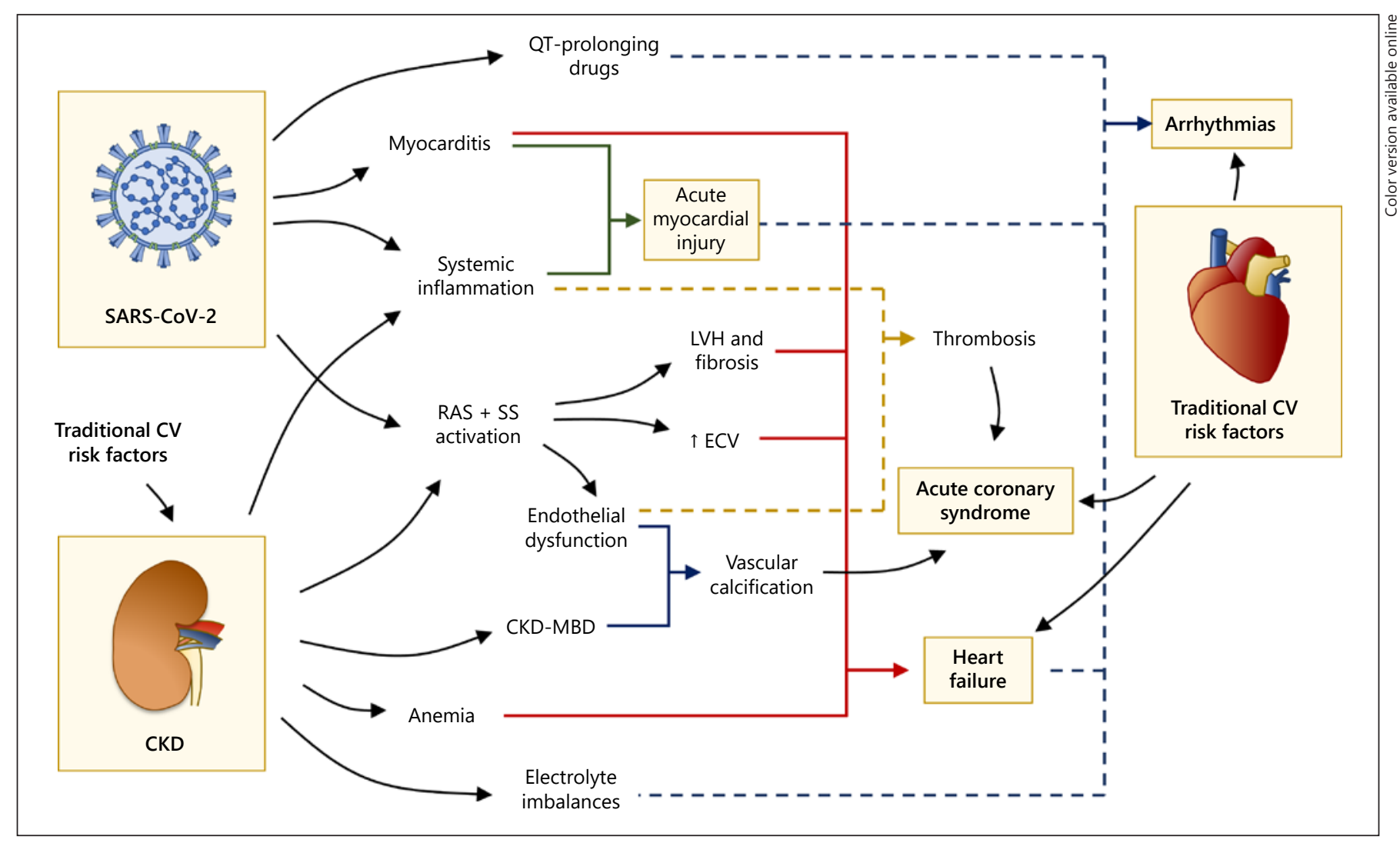

Fig. 1. Effects of SARS-CoV-2 on the cardiovascular system in CKD patients. SARS-CoV-2, severe acute respiratory syndrome coronavirus 2; CV, cardiovascular; ECV, extracellular volume; MBD, mineral-bone disorder; RAS, renin-angiotensin system; SS, sympathetic system.

panied by valvular calcium deposits, which are observed in $12-14 \%$ of patients undergoing maintenance dialysis and may result in valvular stenosis and insufficiency [62].

FGF23 is a key regulator of phosphate homeostasis that inhibits tubular phosphate reabsorption, PTH secretion and vitamin $\mathrm{D}$ activation [63]. The increase in circulating FGF23 levels is one of the earliest evidences of mineral disease in the course of CKD [64]; this mechanism counteracts phosphate accumulation but also induces LVH [65]. Consistently, high FGF23 levels have been associated with cardiovascular morbidity and mortality across several patient cohorts $[66,67]$.

Anemia is an extremely common occurrence in CKD patients, and its prevalence is inversely correlated with CKD severity. Cardiovascular compensation in the setting of anemia produces a state of high output, characterized by decreased vascular resistance, higher heart rate, and increased stroke volume [68]. These features are counterbalanced by a maladaptive increase in RAS and sympathetic nervous system activation, which ultimately results in an abnormally high venous pressure and fluid overload [69]. Anemia has been associated with the development of $\mathrm{LVH}$ in CKD patients [70,71], and this association was found to increase the risk of myocardial infarction, stroke, or death 4-fold [71].

\section{COVID-19 and Cardiovascular Events}

Several features of SARS-CoV-2 infection may explain the high incidence of cardiovascular injury in patients with COVID-19, including direct viral tropism for tissues of the cardiovascular system and indirect mechanisms based on host responses to the infection [72-74]. In addition to pneumonia and acute respiratory distress syndrome, SARS-CoV-2 infection frequently triggers a massive release of proinflammatory cytokines and may induce coagulation abnormalities that increase the risk of cardiovascular events and multiorgan dysfunction (Fig. 1). 
Although still ill-defined, the direct effects of SARSCoV-2 on the RAS and the excessive stimulation of innate immunity have been proposed as pivotal determinants of the pathogenesis of COVID-19-related cardiovascular injury. Cells infected by SARS-CoV-2 internalize the angiotensin-converting enzyme 2 (ACE2) receptor, which is crucial for viral infection, but also regulates the activity of angiotensin II [75]. These cells could potentially downregulate ACE2 expression, as observed in SARS-CoV infection [76, 77], thus reducing angiotensin II inactivation. This may in turn result in increased vasoconstriction, inflammation, and fibrosis. In addition, higher levels of circulating angiotensin II could enhance aldosterone secretion, leading to increased sodium reabsorption and extracellular volume expansion, worsening fluid overload, and possibly precipitating heart failure in patients at risk. As previously discussed, maladaptive RAS activation is common in CKD patients, which likely makes them more vulnerable to these effects.

Moreover, SARS-CoV-2 infection enhances inflammatory responses and increases the release of cytokines (e.g., IL-6 and TNF $\alpha$ ), thereby inducing endothelial activation, myocardial dysfunction, and promoting a prothrombotic environment [5]. CKD is characterized by a chronic state of inflammation, which is further enhanced by additional comorbidities, such as obesity and diabetes. It is therefore conceivable that inflammatory responses elicited by SARS-CoV-2 may be even more deleterious in these patients.

These mechanisms may indeed synergize with the alterations that commonly occur in CKD and may account for the higher morbidity and mortality risk that these patients experience when facing SARS-CoV-2 infection. It is still unclear whether modulating RAS activation could be beneficial in these patients. An intriguing possibility to curtail the effects of the dysregulated cytokine release that accompanies COVID-19 manifestations would be to remove these proinflammatory mediators through the use of extracorporeal methods. In addition to plasma exchange and plasma adsorption on resin cartridges, several methods could be exploited to achieve this aim, including direct hemoperfusion with a neutro-macroporous sorbent, hemodialysis with medium- to high-cutoff membranes, and hemodiafiltration with adsorbent membranes (e.g., AN69-PEI) [78, 79]. Albeit encouraging, preliminary results obtained with these methods still need to be confirmed in larger clinical trials to determine their impact on COVID-19 morbidity and mortality [8082].

\section{Myocardial Injury and Acute Coronary Syndromes}

Evidence of myocardial injury, diagnosed through elevated levels of cardiac biomarkers, was reported in up to $20 \%$ of patients with COVID-19 [4, 83]. Interestingly, creatinine levels were higher in patients who experienced cardiac injury compared to controls; moreover, myocardial injury was associated with a higher risk of developing acute respiratory distress syndrome and patients in this group had an increased in-hospital mortality $[4,84]$.

The mechanisms portending to myocardial injury in patients with COVID-19 are incompletely understood, but the systemic inflammatory state induced by viral infection is likely to play an important role. The imbalance between increased metabolic demand and lower cardiac reserve could be a key player, especially in patients with a past medical history of coronary artery disease. Albeit supported by anecdotal cases only, some authors have suggested that myocardial injury may be a direct consequence of SARS-CoV-2 infection, which could result in viral myocarditis $[85,86]$. Thrombosis due to altered coagulability and systemic inflammation may also destabilize coronary artery plaques, thus triggering acute coronary syndromes [87].

Despite this, a consistent decline in hospitalization rates for acute coronary events has been reported worldwide after SARS-CoV-2 outbreak [88-90], possibly as a consequence of avoidance of care due to fear of infection. This may be particularly problematic in CKD patients, in whom mortality following acute coronary syndrome increases exponentially compared to patients with normal renal function [91]. In addition, inappropriately low rates of coronary angiography in CKD patients with acute coronary syndrome had been already reported in the preCOVID-19 era [92], and this tendency could persist or even worsen in the current situation. Since scant data exist addressing these issues, additional studies are required to clarify the actual incidence and extent of myocardial injury in CKD patients infected by SARS-CoV-2 and to clarify its impact on short- and long-term outcomes.

\section{Arrhythmias}

Arrhythmias are common in patients with COVID-19, with a higher prevalence in those admitted to intensive care units [93]. A recent meta-analysis found that approximately $30 \%$ of patients with severe COVID-19 developed arrhythmias, compared to $3 \%$ of patients with milder disease [94].

Despite this high frequency, the impact of incident cardiac rhythm disorders on mortality in patients with COVID-19 is still unclear. In a recent retrospective study, 
most cardiac rhythm disorders were not associated with increased in-hospital mortality [95]. Another study, however, reported that atrial arrhythmias were independently associated with higher mortality rates [96].

Several factors may contribute to the development of arrhythmias in patients with COVID-19; myocardial injury seems to be a major determinant since patients with elevated cardiac biomarkers experience a higher frequency of arrhythmias [84]. Moreover, inflammatory cytokines may directly affect myocardial cells and increase sympathetic system activation, potentially triggering lifethreatening rhythm disorders [5].

CKD patients with SARS-CoV-2 infection could be particularly susceptible to heart rhythm disorders. Metabolic imbalances, including electrolyte abnormalities such as hypo/hyperkalemia, hypomagnesemia, and hypocalcemia, are frequent in CKD patients and are known to cause prolonged QT interval that, in turn, predisposes to arrhythmias [97]. Indeed, ventricular tachyarrhythmias in COVID-19 patients are mainly associated with severe metabolic derangements [98].

Patients with impaired renal function also exhibit complex pharmacokinetic profiles of drugs with complete or partial renal excretion, a feature that could further complicate management and predispose to malignant arrhythmias. Off-label prescription of drugs such as azithromycin and hydroxychloroquine has now decreased due to evidence of inefficacy [99-101], but these agents may have indeed increased the risk of arrhythmias during the early pandemic, as they are known to prolong QT interval and potentially induce life-threatening arrhythmias. Screening for ECG abnormalities and strict QTc monitoring in patients with CKD may help to define a more precise arrhythmic risk stratification and to guide appropriate and timely management.

\section{Heart Failure}

Acute de novo or worsening of pre-existing heart failure is one of the most common complications of COVID-19, affecting up to 1 quarter of hospitalized patients. The incidence of this condition raises up to $50 \%$ when considering only patients with a fatal outcome $[83,102]$. A retrospective analysis of mortality causes in COVID-19 patients showed that myocardial damage and heart failure contributed to $7 \%$ of fatal cases [103].

Screening for heart failure may be challenging in COVID-19 patients since BNP and NT-proBNP, the most common diagnostic and prognostic biomarkers of myocardial stress and heart failure, are frequently elevated in critically ill patients due to the elevated hemodynamic stress that these patients usually experience. Plasma BNP levels are less affected by glomerular filtration rate compared to NT-proBNP and may thus be a more appropriate biomarker for heart failure in patients with CKD [104].

The pathogenesis of acute heart failure in COVID-19 is incompletely understood, but some of the underlying mechanisms may include myocardial injury, acute coronary syndrome, and sustained cardiac arrhythmias. As previously discussed, these events may be more frequent and potentially more severe in CKD patients; in the general population, CKD is associated with increased morbidity and mortality in heart failure [105]. In addition, complications of CKD such as hypervolemia, systemic inflammation, and anemia could also contribute to acute heart failure development or exacerbation of chronic heart failure in COVID-19 patients. Therefore, COVID-19 patients with heart failure and CKD or renal dysfunction on admission could represent a more susceptible subgroup of patients, in whom a more strict monitoring during hospitalization should be mandated to prevent potentially fatal complications.

Guideline-directed medical therapy recommends treatment of heart failure with ACE inhibitors and angiotensin receptor blockers. The use of these agents at the beginning of the COVID-19 pandemic was highly debated since SARS-CoV-2 utilizes the ACE2 receptors for cell entry and these drugs may upregulate ACE2, thus potentially increasing the susceptibility to the infection. However, there is currently no evidence of an association between ACE inhibitor or angiotensin receptor blocker use and either susceptibility to infection or clinical outcomes [106]; consistent with data from retrospective studies, a recent randomized control trial showed that continuation of RAS inhibitors had no significant effect on a global score comprising time to death, mechanical ventilation, renal replacement or vasopressor therapy, and multiorgan dysfunction [107]. Since withdrawal of medical treatment in patients with heart failure may increase the risk of cardiovascular events, guidelines from both cardiology and nephrology societies do not recommend discontinuation of these agents in case of SARS-CoV-2 infection. Adjustment of medication doses should be considered only in case of hypotension or hemodynamic instability.

\section{Hypercoagulability and Thromboembolism}

COVID-19 is characterized by a hypercoagulable state, which can result in a high incidence of both venous and arterial thrombotic events. In a multicenter retrospective 
cohort study involving 400 patients hospitalized for COVID-19, the overall rate of thrombotic events in noncritically ill patients was $4.7 \%$, which increased to $18.1 \%$ in patients requiring mechanical ventilation [108]. Other studies reported an even higher incidence (25-31\%) of thrombotic events in patients admitted to the intensive care unit $[109,110]$, and there is a seemingly strong association between increased D-dimer levels, consumption of coagulation factors, progression to severe disease, and radiologic features suggesting venous thromboembolism [111].

Though the exact mechanism remains ill-defined, inflammatory responses and endothelial damage induced by COVID-19 have been advocated as key factors in the genesis of this hypercoagulable state. Moreover, many cases of pulmonary artery thrombosis are located in peripheral vessels and are not associated with deep vein thrombosis, suggesting that microangiopathic alterations with local activation of the coagulation cascade induced by endothelial damage and disproportionate inflammation may be responsible for a large fraction of these cases [112].

Owing to this uncertainty, the prevention and management of thrombosis in COVID-19 is still a matter of debate. Most guidelines now agree in recommending anticoagulation prophylaxis with low-molecular-weight heparin for all patients hospitalized due to COVID-19. However, a universal management strategy for critically ill patients has not been established yet. Some authors suggested the use of full- or intermediate-dose anticoagulation in lieu of the high incidence of thrombosis in critically ill patients despite the use of prophylactic low-molecular-weight heparin [108], while others recommend continuation of prophylaxis due to lack of data from randomized clinical trials and the high risk of bleeding reported in these patients [108].

In this context, renal failure may tip the scale toward an even less favorable outcome. CKD is a prothrombotic condition per se, which derives from platelet dysfunction, endothelial injury, and hypercoagulability, leading to thromboembolic complications and to an increased cardiovascular morbidity and mortality [113]. In addition, CKD patients are at increased risk of acute kidney injury and are more likely to require dialysis when hospitalized for COVID-19, which further complicates anticoagulation management.

Overall, the presence of CKD in patients hospitalized due to COVID-19 could worsen a well-known prothrombotic state. Nonetheless, additional data are required to gauge the real impact of CKD on clinical outcomes in this setting.

\section{Conclusions}

The SARS-CoV-2 pandemic has marked the emergence of a novel set of risk factors for patients with CKD and cardiovascular disease, which may have a dreadful impact on clinical outcomes in these high-risk individuals. As knowledge on the many aspects of this worldwide issue is expanding at a remarkably fast pace, indications and therapeutic options are likely to change and evolve over relatively brief periods of time. Clinicians should be aware of the inherent frailty of CKD patients and their high risk of cardiovascular events, which justifies in our view a more strict monitoring. A close collaboration between nephrologists and cardiologists is essential to allow a timely management and to optimize therapeutic strategies in this setting.

\section{Conflict of Interest Statement}

Mario Cozzolino is an associate editor of the journal. All other authors have no conflicts of interest to disclose.

\section{Funding Sources}

There are no funding sources to declare.

\section{Author Contributions}

Manuel Alfredo Podestà, Federica Valli, and Mario Cozzolino wrote the first draft of the article. Andrea Galassi, Matthias Cassia, Paola Ciceri, Lucia Barbieri, and Stefano Carugo critically reviewed and corrected the article.

\section{References}

1 Saran R, Robinson B, Abbott KC, Agodoa LYC, Bragg-Gresham J, Balkrishnan R, et al. US renal data system 2018 annual data report: epidemiology of kidney disease in the United States. Am J Kidney Dis. 2019 Mar;73(3 Suppl 1):A7-8.

2 Kliger AS, Cozzolino M, Jha V, Harbert G, Ikizler TA. Managing the COVID-19 pandemic: international comparisons in dialysis patients. Kidney Int. 2020 Jul;98(1):12-6.

3 Cozzolino M, Piccoli GB, Ikizler TA, Ronco C. The COVID-19 infection in dialysis: are home-based renal replacement therapies a way to improve patient management? Nephrol. 2020;33(4):629-31.

4 Shi S, Qin M, Shen B, Cai Y, Liu T, Yang F, et al. Association of cardiac injury with mortality in hospitalized patients with COVID-19 in Wuhan, China. JAMA Cardiol. 2020 Jul 1; $5(7): 802-10$.

Podestà/Valli/Galassi/Cassia/Ciceri/ Barbieri/Carugo/Cozzolino 
5 Giustino G, Pinney SP, Lala A, Reddy VY, Johnston-Cox HA, Mechanick JI, et al. Coronavirus and cardiovascular disease, myocardial injury, and arrhythmia: JACC focus seminar. J Am Coll Cardiol. 2020 Oct;76(17): 2011-23.

6 Huang C, Wang Y, Li X, Ren L, Zhao J, Hu Y, et al. Clinical features of patients infected with 2019 novel coronavirus in Wuhan, China. Lancet. 2020 Feb;395(10223):497-506.

7 Guan W, Ni Z, Hu Y, Liang W, Ou C, He J, et al. Clinical characteristics of coronavirus disease 2019 in China. N Engl J Med. 2020 Apr; 382(18):1708-20.

8 Gansevoort RT, Hilbrands LB. CKD is a key risk factor for COVID-19 mortality. Nat Rev Nephrol. 2020 Dec;16(12):705-6.

9 Docherty AB, Harrison EM, Green CA, Hardwick HE, Pius R, Norman L, et al. Features of 20133 UK patients in hospital with covid-19 using the ISARIC WHO clinical characterisation protocol: prospective observational cohort study. BMJ. 2020 May;369:m1985.

10 Cheng Y, Luo R, Wang K, Zhang M, Wang Z, Dong L, et al. Kidney disease is associated with in-hospital death of patients with COVID-19. Kidney Int. 2020;97(5):829-38.

11 Chan L, Chaudhary K, Saha A, Chauhan K, Vaid A, Zhao S, et al. AKI in hospitalized patients with COVID-19. J Am Soc Nephrol. 2020 Jan;32(1):151-60.

12 Hajar R. Framingham contribution to cardiovascular disease. Heart Views. 2016;17(2):7881.

13 Vlagopoulos PT, Sarnak MJ. Traditional and nontraditional cardiovascular risk factors in chronic kidney disease. Med Clin North Am. 2005 May;89(3):587-611.

14 Weiner DE, Tighiouart H, Elsayed EF, Griffith JL, Salem DN, Levey AS, et al. The Framingham predictive instrument in chronic kidney disease. J Am Coll Cardiol. 2007 Jul;50(3): 217-24.

15 Iseki K, Iseki C, Ikemiya Y, Fukiyama K. Risk of developing end-stage renal disease in a cohort of mass screening. Kidney Int. 1996 Mar; 49(3):800-5.

16 Afkarian M, Sachs MC, Kestenbaum B, Hirsch IB, Tuttle KR, Himmelfarb J, et al. Kidney disease and increased mortality risk in type 2 diabetes. J Am Soc Nephrol. 2013 Feb; 24(2):302-8.

17 Afkarian M, Katz R, Bansal N, Correa A, Kestenbaum B, Himmelfarb J, et al. Diabetes, kidney disease and cardiovascular outcomes in the Jackson Heart Study. JAMA Cardiol. 2017 Mar;2(3):314-8.

18 Cheung AK, Sarnak MJ, Yan G, Dwyer JT, Heyka RJ, Rocco MV, et al. Atherosclerotic cardiovascular disease risks in chronic hemodialysis patients. Kidney Int. 2000 Jul;58(1): 353-62.

19 Harnett JD, Foley RN, Kent GM, Barre PE, Murray D, Parfrey PS. Congestive heart failure in dialysis patients: prevalence, incidence, prognosis and risk factors. Kidney Int. 1995 Mar;47(3):884-90.
20 Hallan SI, Orth SR. Smoking is a risk factor in the progression to kidney failure. Kidney Int. 2011 Sep;80(5):516-23.

21 Jungers P, Massy ZA, Nguyen Khoa T, Fumeron C, Labrunie M, Lacour B, et al. Incidence and risk factors of atherosclerotic cardiovascular accidents in predialysis chronic renal failure patients: a prospective study. Nephrol Dial Transplant. 1997 Dec;12(12):2597-602.

22 Longenecker JC, Coresh J, Powe NR, Levey AS, Fink NE, Martin A, et al. Traditional cardiovascular disease risk factors in dialysis patients compared with the general population: the CHOICE Study. J Am Soc Nephrol. 2002 Jul;13(7):1918-27.

23 Lazarus JM, Bourgoignie JJ, Buckalew VM, Greene T, Levey AS, Milas NC, et al. Achievement and safety of a low blood pressure goal in chronic renal disease. Hypertension. 1997 Feb;29(2):641-50.

24 Sarafidis P, Loutradis C, Ortiz A, Ruilope LM. Blood pressure targets in patients with chronic kidney disease: MDRD and AASK now confirming SPRINT. Clin Kidney J. 2020 Jun; 13(3):287-90.

25 Zager PG, Nikolic J, Brown RH, Campbell MA, Hunt WC, Peterson D, et al. "U" curve association of blood pressure and mortality in hemodialysis patients. Medical Directors of Dialysis Clinic, Inc. Kidney Int. 1998 Aug; 54(2):561-9.

26 Levin A, Singer J, Thompson CR, Ross H, Lewis M. Prevalent left ventricular hypertrophy in the predialysis population: identifying opportunities for intervention. Am J Kidney Dis. 1996 Mar;27(3):347-54.

27 Di Lullo L, Gorini A, Russo D, Santoboni A, Ronco C. Left ventricular hypertrophy in chronic kidney disease patients: from pathophysiology to treatment. Cardiorenal Med. 2015 Oct;5(4):254-66.

28 Mikolasevic I, Žutelija M, Mavrinac V, Orlic L. Dyslipidemia in patients with chronic kidney disease: etiology and management. Int J Nephrol Renovasc Dis. 2017 Feb;10:35-45.

29 Tonelli M, Muntner P, Lloyd A, Manns B, Klarenbach S, Pannu N, et al. Association between LDL-C and risk of myocardial infarction in CKD. J Am Soc Nephrol. 2013 May; 24(6):979-86

30 Wanner C, Krane V, März W, Olschewski M, Mann JF, Ruf G, et al. Atorvastatin in patients with type 2 diabetes mellitus undergoing hemodialysis. N Engl J Med. 2005 Jul;353(3): $238-48$.

31 Fellström BC, Jardine AG, Schmieder RE, Holdaas H, Bannister K, Beutler J, et al. Rosuvastatin and cardiovascular events in patients undergoing hemodialysis. N Engl J Med. 2009 Apr;360(14):1395-407.

32 Kovesdy CP, Furth SL, Zoccali C. Obesity and kidney disease: hidden consequences of the epidemic. Kidney Dis. 2017 Mar;3(1):33.
33 Ladhani M, Craig JC, Irving M, Clayton PA, Wong G. Obesity and the risk of cardiovascular and all-cause mortality in chronic kidney disease: a systematic review and meta-analysis. Nephrol Dial Transplant. 2017 Mar 1; 32(3):439-49.

34 Manjunath G, Tighiouart H, Ibrahim H, MacLeod B, Salem DN, Griffith JL, et al. Level of kidney function as a risk factor for atherosclerotic cardiovascular outcomes in the community. J Am Coll Cardiol. 2003 Jan; 41(1):47-55.

35 Go AS, Chertow GM, Fan D, McCulloch CE, Hsu CY. Chronic kidney disease and the risks of death, cardiovascular events, and hospitalization. N Engl J Med. 2004 Sep 23;351(13): 1296-305.

36 Gerstein HC, Mann JF, Yi Q, Zinman B, Dinneen SF, Hoogwerf B, et al. Albuminuria and risk of cardiovascular events, death, and heart failure in diabetic and nondiabetic individuals. JAMA. 2001 Jul;286(4):421-6.

37 Wachtell K, Ibsen H, Olsen MH, Borch-Johnsen K, Lindholm LH, Mogensen CE, et al. Albuminuria and cardiovascular risk in hypertensive patients with left ventricular hypertrophy: the LIFE study. Ann Intern Med. 2003 Dec;139(11):901-6.

38 Cozzolino M, Mangano M, Stucchi A, Ciceri P, Conte F, Galassi A. Cardiovascular disease in dialysis patients. Nephrol Dial Transplant. 2018 01;33(Suppl 3):iii28-34.

39 Grassi G, Quarti-Trevano F, Seravalle G, Arenare F, Volpe M, Furiani S, et al. Early sympathetic activation in the initial clinical stages of chronic renal failure. Hypertension. 2011 Apr;57(4):846-51.

40 Converse RL, Jacobsen TN, Toto RD, Jost CM, Cosentino F, Fouad-Tarazi F, et al. Sympathetic overactivity in patients with chronic renal failure. N Engl J Med. 1992 Dec;327(27): 1912-8.

41 Kendrick J, Chonchol MB. Nontraditional risk factors for cardiovascular disease in patients with chronic kidney disease. Nat Clin Pract Nephrol. 2008 Dec;4(12):672-81.

42 Hung SC, Kuo KL, Peng CH, Wu CH, Lien YC, Wang YC, et al. Volume overload correlates with cardiovascular risk factors in patients with chronic kidney disease. Kidney Int. 2014 Mar;85(3):703-9.

43 Kalantar-Zadeh K, Regidor DL, Kovesdy CP, Van Wyck D, Bunnapradist S, Horwich TB, et al. Fluid retention is associated with cardiovascular mortality in patients undergoing long-term hemodialysis. Circulation. 2009 Feb;119(5):671-9.

44 Oberg BP, McMenamin E, Lucas FL, McMonagle E, Morrow J, Ikizler TA, et al. Increased prevalence of oxidant stress and inflammation in patients with moderate to severe chronic kidney disease. Kidney Int. 2004 Mar;65(3):1009-16.

45 Kooman JP, Kotanko P, Schols AM, Shiels PG, Stenvinkel P. Chronic kidney disease and premature ageing. Nat Rev Nephrol. 2014 Dec;10(12):732-42. 
46 Jankowska M, Cobo G, Lindholm B, Stenvinkel P. Inflammation and protein-energy wasting in the uremic milieu. Contrib Nephrol. 2017;191:58-71.

47 Ioannou K, Stel VS, Dounousi E, Jager KJ, Papagianni A, Pappas K, et al. Inflammation, endothelial dysfunction and increased left ventricular mass in chronic kidney disease (CKD) patients: a Longitudinal Study. PLoS One. 2015 Sep;10(9):e0138461.

48 Arici M, Walls J. End-stage renal disease, atherosclerosis, and cardiovascular mortality: is C-reactive protein the missing link? Kidney Int. $2001 \mathrm{Feb}$;59(2):407-14.

49 Weiner DE, Tighiouart H, Elsayed EF, Griffith JL, Salem DN, Levey AS, et al. The relationship between nontraditional risk factors and outcomes in individuals with stage 3 to 4 CKD. Am J Kidney Dis. 2008 Feb;51(2):21223.

50 Menon V, Greene T, Wang X, Pereira AA, Marcovina SM, Beck GJ, et al. C-reactive protein and albumin as predictors of all-cause and cardiovascular mortality in chronic kidney disease. Kidney Int. 2005 Aug;68(2):76672.

51 Yeun JY, Levine RA, Mantadilok V, Kaysen GA. C-reactive protein predicts all-cause and cardiovascular mortality in hemodialysis patients. Am J Kidney Dis. 2000 Mar;35(3):46976.

52 Dounousi E, Papavasiliou E, Makedou A, Ioannou K, Katopodis KP, Tselepis A, et al. Oxidative stress is progressively enhanced with advancing stages of CKD. Am J Kidney Dis. 2006 Nov;48(5):752-60.

53 Nakagami H, Takemoto M, Liao JK. NADPH oxidase-derived superoxide anion mediates angiotensin II-induced cardiac hypertrophy. J Mol Cell Cardiol. 2003 Jul;35(7):851-9.

54 Tumur Z, Niwa T. Indoxyl sulfate inhibits nitric oxide production and cell viability by inducing oxidative stress in vascular endothelial cells. Am J Nephrol. 2009;29(6):551-7.

55 Perticone F, Sciacqua A, Maio R, Perticone M, Maas R, Boger RH, et al. Asymmetric dimethylarginine, L-arginine, and endothelial dysfunction in essential hypertension. J Am Coll Cardiol. 2005 Aug;46(3):518-23.

56 Cachofeiro V, Goicochea M, de Vinuesa SG, Oubiña P, Lahera V, Luño J. Oxidative stress and inflammation, a link between chronic kidney disease and cardiovascular disease. Kidney Int Suppl. 2008 Dec(111):S4-9.

57 Daenen K, Andries A, Mekahli D, Van Schepdael A, Jouret F, Bammens B. Oxidative stress in chronic kidney disease. Pediatr Nephrol. 2019;34(6):975-91.

58 McGovern AP, de Lusignan S, van Vlymen J, Liyanage H, Tomson CR, Gallagher H, et al. Serum phosphate as a risk factor for cardiovascular events in people with and without chronic kidney disease: a large community based cohort study. PLoS One. 2013;8(9): e74996.
59 Vervloet MG, Sezer S, Massy ZA, Johansson L, Cozzolino M, Fouque D, et al. The role of phosphate in kidney disease. Nat Rev Nephrol. 2017 Jan;13(1):27-38.

60 Cozzolino M, Ciceri P, Galassi A, Mangano M, Carugo S, Capelli I, et al. The key role of phosphate on vascular calcification. Toxins. 2019 Apr 9;11(4):213.

61 Chen J, Budoff MJ, Reilly MP, Yang W, Rosas SE, Rahman M, et al. Coronary artery calcification and risk of cardiovascular disease and death among patients with chronic kidney disease. JAMA Cardiol. 2017 Jun 1;2(6):63543.

62 Marwick TH, Amann K, Bangalore S, Cavalcante JL, Charytan DM, Craig JC, et al. Chronic kidney disease and valvular heart disease: conclusions from a kidney disease: improving global outcomes (KDIGO) controversies conference. Kidney Int. 2019 Oct; 96(4):836-49.

63 Galassi A, Cupisti A, Santoro A, Cozzolino M. Phosphate balance in ESRD: diet, dialysis and binders against the low evident masked pool. J Nephrol. 2015 Aug;28(4):415-29.

$64 \mathrm{Hu}$ MC, Kuro-o M, Moe OW. The emerging role of Klotho in clinical nephrology. Nephrol Dial Transplant. 2012 Jul;27(7):2650-7.

65 Faul C, Amaral AP, Oskouei B, Hu MC, Sloan A, Isakova T, et al. FGF23 induces left ventricular hypertrophy. J Clin Invest. 2011 Nov; 121(11):4393-408.

66 Gutiérrez OM, Mannstadt M, Isakova T, Rauh-Hain JA, Tamez H, Shah A, et al. Fibroblast growth factor 23 and mortality among patients undergoing hemodialysis. N Engl J Med. 2008 Aug;359(6):584-92.

67 Isakova T, Xie H, Yang W, Xie D, Anderson AH, Scialla J, et al. Fibroblast growth factor 23 and risks of mortality and end-stage renal disease in patients with chronic kidney disease. JAMA. 2011 Jun;305(23):2432-9.

68 Weiskopf RB, Viele MK, Feiner J, Kelley S, Lieberman J, Noorani M, et al. Human cardiovascular and metabolic response to acute, severe isovolemic anemia. JAMA. 1998 Jan; 279(3):217-21.

69 Anand IS. Pathophysiology of anemia in heart failure. Heart Fail Clin. 2010 Jul;6(3):279-88.

70 Levin A, Thompson CR, Ethier J, Carlisle EJ, Tobe S, Mendelssohn D, et al. Left ventricular mass index increase in early renal disease: impact of decline in hemoglobin. Am J Kidney Dis. 1999 Jul;34(1):125-34.

71 Weiner DE, Tighiouart H, Vlagopoulos PT, Griffith JL, Salem DN, Levey AS, et al. Effects of anemia and left ventricular hypertrophy on cardiovascular disease in patients with chronic kidney disease. J Am Soc Nephrol. 2005 Jun; 16(6):1803-10.

72 Nishiga M, Wang DW, Han Y, Lewis DB, Wu JC. COVID-19 and cardiovascular disease: from basic mechanisms to clinical perspectives. Nat Rev Cardiol. 2020 Sep;17(9):54358.
73 Driggin E, Madhavan MV, Bikdeli B, Chuich T, Laracy J, Biondi-Zoccai G, et al. Cardiovascular considerations for patients, health care workers, and health systems during the COVID-19 pandemic. J Am Coll Cardiol. 2020 May 12;75(18):2352-71.

74 Topol EJ. COVID-19 can affect the heart. Science. 2020 Oct;370(6515):408-9.

75 Zores F, Rebeaud ME. COVID and the reninangiotensin system: are hypertension or its treatments deleterious? Front Cardiovasc Med. 2020;7:71.

76 Kuba K, Imai Y, Rao S, Gao H, Guo F, Guan $\mathrm{B}$, et al. A crucial role of angiotensin converting enzyme 2 (ACE2) in SARS coronavirusinduced lung injury. Nat Med. 2005 Aug; 11(8):875-9.

77 Oudit GY, Kassiri Z, Jiang C, Liu PP, Poutanen SM, Penninger JM, et al. SARS-coronavirus modulation of myocardial ACE2 expression and inflammation in patients with SARS. Eur J Clin Invest. 2009 Jul;39(7):61825.

78 Ronco C, Reis T, Cozzolino M. Rationale for medium cutoff membranes in COVID-19 patients requiring renal replacement therapy. Nephron. 2020;144(11):550-4.

79 Ronco C, Reis T. Kidney involvement in COVID-19 and rationale for extracorporeal therapies. Nat Rev Nephrol. 2020 Jun;16(6):30810.

80 Villa G, Romagnoli S, De Rosa S, Greco M, Resta M, Pomarè Montin D, et al. Blood purification therapy with a hemodiafilter featuring enhanced adsorptive properties for cytokine removal in patients presenting $\mathrm{CO}$ VID-19: a pilot study. Crit Care. 2020 Oct; 24(1):605.

81 Nalesso F, Garzotto F, Cattarin L, Gobbi L, Qassim L, Sgarabotto L, et al. A continuous renal replacement therapy protocol for patients with acute kidney injury in intensive care unit with COVID-19. J Clin Med. 2020 May 19;9(5):1529.

82 Asgharpour M, Mehdinezhad H, Bayani M, Zavareh MSH, Hamidi SH, Akbari R, et al. Effectiveness of extracorporeal blood purification (hemoadsorption) in patients with severe coronavirus disease 2019 (COVID-19). BMC Nephrol. 2020 Aug;21(1):356.

83 Zhou F, Yu T, Du R, Fan G, Liu Y, Liu Z, et al Clinical course and risk factors for mortality of adult inpatients with COVID-19 in Wuhan, China: a retrospective cohort study. Lancet. 2020 Mar;395(10229):1054-62.

84 Guo T, Fan Y, Chen M, Wu X, Zhang L, He T, et al. Cardiovascular implications of fatal outcomes of patients with coronavirus disease 2019 (COVID-19). JAMA Cardiol. 2020 Jul 1; 5(7):811-8.

85 Inciardi RM, Lupi L, Zaccone G, Italia L, Raffo $\mathrm{M}$, Tomasoni $\mathrm{D}$, et al. Cardiac involvement in a patient with coronavirus disease 2019 (COVID-19). JAMA Cardiol. 2020 Jul 1;5(7): 819-24. 
86 Wang S, Wei X, Hu H. STAR evidence evaluation of viral fulminant myocarditis: specificity, timeliness, accessibility, risk. Eur Heart J. 2020 Sep;41(34):3281-2.

87 Libby P, Loscalzo J, Ridker PM, Farkouh ME, Hsue PY, Fuster V, et al. Inflammation, immunity, and infection in atherothrombosis: JACC review topic of the week. J Am Coll Cardiol. 2018 Oct 23;72(17):2071-81.

88 Solomon MD, McNulty EJ, Rana JS, Leong TK, Lee C, Sung SH, et al. The Covid-19 pandemic and the incidence of acute myocardial infarction. N Engl J Med. 2020 Aug;383(7): 691-3.

89 Mafham MM, Spata E, Goldacre R, Gair D, Curnow P, Bray M, et al. COVID-19 pandemic and admission rates for and management of acute coronary syndromes in England. Lancet. 2020 Aug;396(10248):381-9.

90 De Rosa S, Spaccarotella C, Basso C, Calabrò MP, Curcio A, Filardi PP, et al. Reduction of hospitalizations for myocardial infarction in Italy in the COVID-19 era. Eur Heart J. 2020 Jun 7;41(22):2083-8.

91 Masoudi FA, Plomondon ME, Magid DJ, Sales A, Rumsfeld JS. Renal insufficiency and mortality from acute coronary syndromes. Am Heart J. 2004 Apr;147(4):623-9.

92 Chertow GM, Normand SL, McNeil BJ. "Renalism": inappropriately low rates of coronary angiography in elderly individuals with renal insufficiency. J Am Soc Nephrol. 2004 Sep;15(9):2462-8.

93 Wang D, Hu B, Hu C, Zhu F, Liu X, Zhang J, et al. Clinical characteristics of 138 hospitalized patients with 2019 novel coronavirus-infected pneumonia in Wuhan, China. JAMA. 2020 Mar 17;323(11):1061-9.

94 Wen W, Zhang H, Zhou M, Cheng Y, Ye L, Chen J, et al. Arrhythmia in patients with severe coronavirus disease (COVID-19): a meta-analysis. Eur Rev Med Pharmacol Sci. 2020;24(21):11395-401.

95 Bhatla A, Mayer MM, Adusumalli S, Hyman MC, Oh E, Tierney A, et al. COVID-19 and cardiac arrhythmias. Heart Rhythm. 2020 Sep;17(9):1439-44.
96 Peltzer B, Manocha KK, Ying X, Kirzner J, Ip JE, Thomas G, et al. Outcomes and mortality associated with atrial arrhythmias among patients hospitalized with COVID-19. J Cardiovasc Electrophysiol. 2020 Oct.

97 Liu P, Wang L, Han D, Sun C, Xue X, Li G. Acquired long QT syndrome in chronic kidney disease patients. Ren Fail. 2019 Dec; 42(1):54-65.

98 Turagam MK, Musikantow D, Goldman ME, Bassily-Marcus A, Chu E, Shivamurthy $\mathrm{P}$, et al. Malignant arrhythmias in patients with COVID-19: incidence, mechanisms, and outcomes. Circ Arrhythm Electrophysiol. 2020;13(11):e008920.

99 Cavalcanti AB, Zampieri FG, Rosa RG, Azevedo LCP, Veiga VC, Avezum A, et al. Hydroxychloroquine with or without azithromycin in mild-to-moderate Covid-19. N Engl J Med. 2020 Nov;383(21):2041-52.

100 Furtado RHM, Berwanger O, Fonseca HA, Corrêa TD, Ferraz LR, Lapa MG, et al. Azithromycin in addition to standard of care versus standard of care alone in the treatment of patients admitted to the hospital with severe COVID-19 in Brazil (COALITION II): a randomised clinical trial. Lancet. 2020 Oct;396(10256):959-67.

101 WHO Solidarity Trial Consortium; Pan H, Peto R, Karim QA, Alejandria M, HenaoRestrepo AM, et al. Repurposed antiviral drugs for COVID-19: interim WHO solidarity trial results. medRxiv. 2020 Oct.

102 Chen T, Wu D, Chen H, Yan W, Yang D, Chen $\mathrm{G}$, et al. Clinical characteristics of 113 deceased patients with coronavirus disease 2019: retrospective study. BMJ. 2020 Mar; 368:m1091.

103 Ruan Q, Yang K, Wang W, Jiang L, Song J. Clinical predictors of mortality due to $\mathrm{CO}$ VID-19 based on an analysis of data of 150 patients from Wuhan, China. Intensive Care Med. 2020 May;46(5):846-8.

104 Tagore R, Ling LH, Yang H, Daw HY, Chan $\mathrm{YH}$, Sethi SK. Natriuretic peptides in chronic kidney disease. Clin J Am Soc Nephrol. 2008 Nov;3(6):1644-51.
105 Heywood JT, Fonarow GC, Costanzo MR, Mathur VS, Wigneswaran JR, Wynne J, et al. High prevalence of renal dysfunction and its impact on outcome in 118,465 patients hospitalized with acute decompensated heart failure: a report from the ADHERE database. J Card Fail. 2007 Aug;13(6):422-30.

106 Vaduganathan M, Vardeny O, Michel T, McMurray JJV, Pfeffer MA, Solomon SD. Renin-angiotensin-aldosterone system inhibitors in patients with Covid-19. N Engl J Med. 2020 Apr;382(17):1653-9.

107 Cohen JB, Hanff TC, William P, Sweitzer N, Rosado-Santander NR, Medina C, et al. Continuation versus discontinuation of renin-angiotensin system inhibitors in patients admitted to hospital with COVID-19: a prospective, randomised, open-label trial. Lancet Respir Med. 2021 Jan.

108 Al-Samkari H, Karp Leaf RS, Dzik WH, Carlson JCT, Fogerty AE, Waheed A, et al. COVID-19 and coagulation: bleeding and thrombotic manifestations of SARS-CoV-2 infection. Blood. 2020 Jul;136(4):489-500.

109 Klok FA, Kruip MJHA, van der Meer NJM, Arbous MS, Gommers DAMPJ, Kant KM, et al. Incidence of thrombotic complications in critically ill ICU patients with COVID-19. Thromb Res. 2020 Jul;191:145-7.

110 Cui S, Chen S, Li X, Liu S, Wang F. Prevalence of venous thromboembolism in patients with severe novel coronavirus pneumonia. J Thromb Haemost. 2020;18(6): 1421-4.

111 Oudkerk M, Büller HR, Kuijpers D, van Es N, Oudkerk SF, McLoud T, et al. Diagnosis, prevention, and treatment of thromboembolic complications in COVID-19: report of the national institute for public health of the Netherlands. Radiology. 2020 Apr;297(1): E216-22.

112 Chowdhury JF, Moores LK, Connors JM Anticoagulation in hospitalized patients with Covid-19. N Engl J Med. 2020 Oct; 383(17):1675-8.

113 Aursulesei V, Costache II. Anticoagulation in chronic kidney disease: from guidelines to clinical practice. Clin Cardiol. 2019 May; 42(8):774-82. 